\title{
PENGARUH MODEL PEMBELAJARAN BERBASIS MASALAH TERHADAP KEMAMPUAN BERPIKIR KRITIS DAN KEMAMPUAN BERPIKIR KREATIF
}

\author{
NOVRITA MULYA ROSA \\ ANIK PUJIATI \\ muly4ros4@gmail.com, anikrahmany@yahoo.com \\ Program Studi Pendidikan Matematika, FTMIPA \\ Universitas Indraprasta PGRI, Jakarta
}

\begin{abstract}
Abstrak. Tujuan dari penelitian adalah untuk mengetahui pengaruh model pembelajaran berbasis masalah terhadap kemampuan berpikir kritis dan kemampuan berpikir kreatif. Subjek penelitian adalah mahasiswa Program Studi Pendidikan Matematika Universitas Indraprasta PGRI semester IV tahun akademik 2013/2014 berjumlah 60 orang, pada mata kuliah Kimia Dasar II. Pemilihan kelas sampel menggunakan teknik multistage random sampling. Penelitian dilakukan pada sampel yang terdiri dari 30 mahasiswa kelas eksperimen dengan model pembelajaran berbasis masalah dan 30 mahasiswa kelas kontrol dengan model pembelajaran ekspositori. Teknik pengumpulan data dilakukan dengan melaksanakan tes kemampuan berpikir kritis dan kreatif kimia berupa soal uraian. Analisa data penelitian menggunakan MANOVA dengan bantuan program SPSS. Dari hasil penelitian disimpulkan bahwa ada pengaruh model pembelajaran terhadap kemampuan berpikir kritis dan kemampuan berpikir kreatif secara bersama-sama $(\mathrm{F}=21,815 ; \mathrm{p}=0.000)$.
\end{abstract}

Kata kunci: pembelajaran berbasis masalah, kemampuan berpikir kritis, kemampuan berpikir kreatif.

\begin{abstract}
The purpose of the study was to determine the role of problem based learning model to critical thinking ability and creative thinking ability. The subjects were students of semester IV Mathematic Education Study Program, University of Indraprasta PGRI, Jakarta in 2013/2014, in the subject of Basic Chemistry II. The selection of the class for this study was based on multistage random sampling. Experiments conducted on sample of 30 experimental class students with problem based learning model and 30 control class students with expository learning model. The data was collected by implementing tests of critical thinking ability and creative thinking ability with essay test. Analysis of research data using MANOVA support by SPSS. From the results of the study concluded that learning models give influence to the critical thinking ability and creative thinking abiliy together $(F=21,815 ; p=0.000)$.
\end{abstract}

Keywords: learning model, critical thinking ability, creative thinking ability

\section{PENDAHULUAN}

Kemampuan pemecahan masalah, berpikir kritis dan berpikir kreatif merupakan hakekat tujuan pendidikan dan menjadi kebutuhan bagi mahasiswa untuk menghadapi dunia nyata (Santyasa,2004). Pendapat senada juga disampaikan oleh Hasratudin (2010) bahwa kemampuan berpikir kritis yang baik dapat membentuk sikap-perilaku yang rasional. Jadi, meningkatkan kemampuan berpikir kritis sangat perlu dan urgen untuk dikembangkan terlebih pada masa sekarang yang penuh dengan permasalahan dan tantangan hidup. Dengan demikian, tidak berlebihan apabila disektor pendidikan mengharuskan untuk mempersiapkan generasi penerus bangsa untuk menjadi pemikir- 
pemikir yang kritis sehingga mampu menghadapi berbagai tantangan dan dapat bertahan hidup secara dengan penuh rasa percaya diri.

Pemikiran kritis, sistematis, logis, kreatif, kemauan dan kerjasama merupakan bagian dari kemampuan berpikir dari setiap orang. Kemampuan berpikir seperti ini dapat dikreasikan melalui pembelajaran kimia, sebab di dalam kimia terdapat struktur dan karakteristik serta keterkaitan yang kuat dan jelas antara konsep yang satu dengan konsep lainnya, sehingga memungkinkan semua mahasiswa dapat berpikir kemampuan rasional dan nyata. Untuk itu proses pembelajaran kimia yang telah ada selama ini perlu ditingkatkan dan didesain sedemikian rupa dengan kondisi belajar yang berdaya tarik dan menyenangkan sehingga mahasiswa lebih bersemangat, bergairah dan tertarik terhadap kimia.

Saat ini, pendidikan masih kurang menunjang tumbuh dan berkembangnya kemampuan kreativitas peserta didik. Kenyataannya bidang pendidikan lebih menekankan kepada pemikiran tidak produktif, hapalan, dan mencari satu jawaban yang benar saja, akibatnya kreativitas mahasiswa pun dapat terhambat. Proses pemikiran yang tinggi termasuk berpikir kreatif jarang sekali dilatih sehingga pembelajaran seperti ini dapat menimbulkan kekakuan dalam proses berpikir dan kurang luas dalam meninjau suatu masalah. Pada dasarnya bakat dasar kreatif itu dimiliki oleh setiap orang, karena setiap orang memiliki kecenderungan atau dorongan untuk mewujudkan potensinya.

Pemberian masalah dalam kegiatan belajar, akan membuat mahasiswa lebih tertarik sehingga dapat merangsang mereka untuk lebih aktif. Hal tersebut dikarenakan di dalam pembelajaran mahasiswa dituntut untuk dapat menyelesaikan masalah dengan melakukan investigasi dan penyelidikan. Penerapan pembelajaran berdasarkan masalah dapat melatih mahasiswa berpikir kritis, menganalisis dan memecahkan masalah komplek, dapat bekerja secara kooperatif di dalam tim kecil, meningkatkan kemampuan berkomunikasi dengan efektif baik verbal maupun tertulis (Barbara,2001)

Berdasarkan dari paparan di atas, peneliti tertarik untuk mengetahui pengaruh model pembelajaran terhadap kemampuan berpikir kritis dan

\section{TINJAUAN PUSTAKA}

\section{Kemampuan Berpikir Kritis}

Secara umum ada berbagai makna berpikir kritis, Menurut McGregor (2007) berpikir kritis meliputi (a) mengidentifikasi unsur-unsur yang merupakan alasan dari kasus, khususnya hubungan sebab- akibat; (b) mengidentifikasi dan mengevaluasi asumsi; (c) menjelaskan dan menginterpretasikan pernyataan dan ide; (d) menimbang keterterimaan, khususnya kredibilitas klaim; (e) mengevaluasi berbagai jenis argumen; (f) menganalisis, mengevaluasi dan membuat kesimpulan; (g) menarik kesimpulan; (h) menghasilkan argumen.

Berpikir kritis memerlukan pertimbangan yang menurut Joanne Kurfiss (Inch, et al., 2006) adalah sebagai berikut: An investigation whose purpose to explore a situation, phenomenon, question, or problem to arrive at a hypothesis or conclusion about it that integrates all available information and that therefore can be convincingly justified. Jadi, berpikir kritis merupakan penyelidikan yang diperlukan untuk mengeksplorasi situasi, fenomena, pertanyaan atau masalah untuk menyusun hipotesis atau konklusi, yang memadukan semua informasi yang dimungkinkan dan dapat diyakini kebenarannya.

\section{Kemampuan Berpikir Kreatif}

Guilford dalam Fasco (2001) menyatakan bahwa "a creative act is an instance of learning...[and that] a comprehensive learning theory must take into account both insight and creative activity". Kreativitas merupakan suatu sisi dari manusia yang 
menandai "manusianya" seorang manusia. Karena kreativitas inilah maka manusia dapat berada pada kemajuan di berbagai bidang kehidupan seperti sekarang ini. Munandar (2009) menyatakan bahwa berpikir kreatif disebut juga berpikir divergen atau kebalikan dari berpikir konvergen. Berpikir divergen yaitu berpikir untuk memberikan macammacam kemungkinan jawaban benar ataupun cara terhadap suatu masalah berdasarkan informasi yang diberikan dengan penekanan pada jumlah dan kesesuaian. Sedangkan, berpikir konvergen yaitu berpikir untuk memberikan satu jawaban terhadap suatu masalah berdasarkan informasi yang diberikan.

Menurut (Filsaime, 2008), berpikir kreatif adalah proses berpikir yang memiliki ciri-ciri kelancaran (fluency), keluwesan (flexibility), keaslian atau originalitas (originality) dan merinci atau elaborasi (elaboration). Kelancaran adalah kemampuan mengeluarkan ide atau gagasan yang benar sebanyak mungkin secara jelas. Keluwesan adalah kemampuan untuk mengeluarkan banyak ide atau gagasan yang beragam dan tidak monoton dengan melihat dari berbagai sudut pandang. Originalitas adalah kemampuan untuk mengeluarkan ide atau gagasan yang unik dan tidak biasanya, misalnya yang berbeda dari yang ada di buku atau berbeda dari pendapat orang lain. Elaborasi adalah kemampuan untuk menjelaskan faktor-faktor yang mempengaruhi dan menambah detail dari ide atau gagasannya sehingga lebih bernilai.

Coleman and Hammen dalam (Rohaeti, 2010) menyebutkan bahwa creative thinking was a way of thinking which produce a new concept, finding, or art creation. Secara singkat berpikir kreatif dapat dikatakan sebagai pola berpikir yang didasarkan pada suatu cara yang mendorong kita untuk menghasilkan produk yang kreatif. Jika kita hubungkan dengan ilmu kimia, maka hasil dari kemampuan berpikir kreatif kimia akan menghasilkan terobosan baru penyelesaian masalah kimia yang baru, tentunya yang lebih fleksibel, dan lebih menarik. Selain itu, mahasiswa juga dapat menghasilkan produkproduk baru dalam bidang kimia yang sangat dibutuhkan masyarakat saat ini.

Dari seluruh pendapat ahli di atas dapat disimpulkan bahwa Kemampuan Berpikir Kreatif Kimia adalah kemampuan mendayagunakan pikiran untuk mengungkapkan ide atau gagasan mengenai konsep kimia ataupun kemampuan mencari penyelesaian masalah kimia dengan cara yang kreatif dan beragam. Kemampuan ini memiliki ciri-ciri kelancaran (fluency), keluwesan (flexibility), keaslian atau originalitas (originality) dan merinci atau elaborasi (elaboration) dan evaluasi (evaluation).

\section{Model Pembelajaran Berbasis Masalah (PBM)}

Menurut Arends dalam Trianto (2007), pengajaran berdasarkan masalah merupakan suatu pendekatan pembelajaran dimana peserta didik mengerjakan permasalahan yang otentik dengan maksud untuk menyusun pengetahuan mereka sendiri, mengembangkan inkuiri dan ketrampilan tingkat lebih tinggi, mengembangkan kemandirian dan percaya diri. Lebih lanjut Arends menyatakan bahwa esensi Pembelajaran Berdasarkan Masalah merupakan penyuguhan berbagai situasi bermasalah yang autentik dan bermakna kepada mahasiswa yang dapat berfungsi sebagai batu loncatan untuk investigasi dan penyelidikan. Hidayat (2011) mengatakan bahwa model Problem Based Learning merupakan bentuk pembelajaran yang menekankan pada pengalaman belajar agar peserta didik dapat merekonstruk pengetahuannya sendiri melalui penyajian masalah yang nyata sehingga mampu belajar secara mandiri. Kelebihan penerapan PBM antara lain melatih kemampuan berpikir dan ketrampilan mengatasi masalah, meniru peran orang dewasa dalam menghadapi situasi nyata, dan melatih belajar secara mandiri. 


\section{METODE}

Penelitian dilaksanakan pada Program Studi Pendidikan Matematika Universitas Indraprasta PGRI, Jakarta Selatan. Populasi pada penelitian ini adalah mahasiswa yang terdaftar pada semester genap tahun akademik 2013/2014 yang mengikuti mata kuliah Kimia Dasar II. Untuk pengambilan sampel pada penelitian ini diambil para mahasiswa yang tergabung dalam populasi terjangkau diambil dua kelas secara acak. Kelas pertama yaitu sebanyak 30 mahasiswa sebagai kelompok eksperimen. Kelas kedua, yaitu sebanyak 30 mahasiswa sebagai kelompok kontrol. Dalam pengambilan sampel peneliti mengambil teknik sampling multi stage random sampling.

Penelitian ini menggunakan metode penelitian kuasi eksperimen (quasi experiment). Kelas pertama diberi perlakuan dengan model pembelajaran berbasis masalah. Kemudian kelas kedua diberi perlakuan model pembelajaran ekspositori. Desain penelitiannya dapat dilihat pada Tabel 1 .

Tabel 1. Desain Penelitian

\begin{tabular}{|c|c|c|c|c|c|}
\hline \multirow{2}{*}{ Model Pembelajaran } & \multicolumn{2}{|c|}{$\begin{array}{c}\text { PBM } \\
\left(\mathrm{A}_{1}\right)\end{array}$} & \multicolumn{2}{c|}{$\begin{array}{c}\text { Ekspositori } \\
\left(\mathrm{A}_{2}\right)\end{array}$} & \multirow{2}{*}{ Jumlah } \\
\cline { 2 - 5 } & $\mathrm{Y}_{1}$ & $\mathrm{Y}_{2}$ & $\mathrm{Y}_{1}$ & $\mathrm{Y}_{2}$ & \\
\hline \multirow{2}{*}{ Jumlah } & $\Sigma$ & $\Sigma$ & $\Sigma$ & $\Sigma$ & $\Sigma$ \\
\hline
\end{tabular}

Teknik pengumpulan data dalam penelitian ini menggunakan metode tes untuk melihat kemampuan berpikir kritis dan kemampuan berpikir kreatif kimia. Pada penelitian ini akan diteliti kemampuan berpikir kritis kimia dan kemampuan berpikir kreatif kimia mahasiswa dalam memecahkan masalah yang berkaitan dengan laju reaksi dan koloid.

Uji Normalitas yang digunakan adalah analisis Kolmogorov Smirnov dan Uji Homogenitas varians-kovarians dilakukan dengan menggunakan analisis Box's Test. Hipotesis dalam penelitian diuji dengan menggunakan uji statistik MANOVA. Semua uji dilakukan menggunakan program SPSS.

\section{HASIL PENELITIAN DAN PEMBAHASAN Deskripsi Data}

Tabel 2. Deskripsi Nilai Kemampuan Berpikir Kritis

\begin{tabular}{|l|l|l|}
\hline \multirow{2}{*}{ Statistik } & \multicolumn{2}{|c|}{ Model Pembelajaran } \\
\cline { 2 - 3 } & \multicolumn{1}{|c|}{ PBM } & \multicolumn{1}{c|}{ Ekspo } \\
\hline Mean & 48,9 & 35,43 \\
\hline Median & 50 & 35 \\
\hline SD & 4,671 & 8,58 \\
\hline Varians & 21,82 & 73,7 \\
\hline Minimum & 39 & 12 \\
\hline Maksimum & 56 & 54 \\
\hline Jangkauan & 17 & 42 \\
\hline
\end{tabular}


Tabel 3. Deskripsi Nilai Kemampuan Berpikir Kreatif

\begin{tabular}{|l|l|l|}
\hline \multirow{2}{*}{ Statistik } & \multicolumn{2}{|c|}{ Model Pembelajaran } \\
\cline { 2 - 3 } & \multicolumn{1}{|c|}{ PBM } & \multicolumn{1}{|c|}{ Ekspo } \\
\hline Mean & 26,87 & 20,7 \\
\hline Median & 26 & 20 \\
\hline SD & 4,48 & 5,1 \\
\hline Varians & 20,12 & 25,7 \\
\hline Minimum & 17 & 10 \\
\hline Maksimum & 34 & 34 \\
\hline Jangkauan & 17 & 24 \\
\hline
\end{tabular}

\section{Pengujian Persyaratan Analisis Data}

Dalam menganalisis data dengan menggunakan MANOVA diperlukan uji normalitas dan Homogenitas varians-covarians. Uji normalitas Kolmogrov Smirnov dan uji homogenitas varians-covarians menunjukkan nilai sig $>0,05$ sehingga sampel dinyatakan berdistribusi normal dan memiliki kesamaan varians-covarians.

\section{Pengujian Hipotesis}

Pengujian hipotesis penelitian menggunakan analisis MANOVA dengan program SPSS, diperoleh output yang digambarkan dalam Tabel 4.

Tabel 4. Ouput SPSS Hasil MANAVA

Multivariate Tests ${ }^{b}$

\begin{tabular}{|c|c|c|c|c|c|c|}
\hline Effect & & Value & F & $\begin{array}{c}\text { Hypothesis } \\
\text { df }\end{array}$ & $\begin{array}{c}\text { Error } \\
\text { df }\end{array}$ & Sig. \\
\hline \multirow[t]{7}{*}{ Intercept } & Pillai's Trace & ,974 & 1061,542 & 2,000 & 57,00 &, 000 \\
\hline & Wilks' & ,026 & 1061,542 & 2,000 & 57,00 &, 000 \\
\hline & Lambda & & & & 0 & \\
\hline & Hotelling's & 37,247 & 1061,542 & 2,000 & 57,00 &, 000 \\
\hline & Trace & & & & 0 & \\
\hline & Roy's & 37,247 & 1061,542 & 2,000 & 57,00 &, 000 \\
\hline & Largest Root & & $a$ & & 0 & \\
\hline \multirow{7}{*}{$\begin{array}{l}\text { Model_Pembe } \\
\text { lajaran }\end{array}$} & Pillai's Trace & ,434 & $21,815^{\mathrm{a}}$ & 2,000 & 57,00 & ,000 \\
\hline & Wilks' & ,566 & $21,815^{\mathrm{a}}$ & 2,000 & 57,00 &, 000 \\
\hline & Lambda & & & & 0 & \\
\hline & Hotelling's & ,765 & $21,815^{\mathrm{a}}$ & 2,000 & 57,00 &, 000 \\
\hline & Trace & & & & & \\
\hline & Roy's & ,765 & $21,815^{\mathrm{a}}$ & 2,000 & 57,00 &, 000 \\
\hline & Largest Root & & & & 0 & \\
\hline
\end{tabular}

a. Exact statistic

b. Design: Intercept + Model_Pembelajaran 
Tabel 5. Uji Pengaruh masing-masing Variabel Bebas terhadap Variabel Terikat Tests of Between-Subjects Effects

\begin{tabular}{|c|c|c|c|c|c|c|}
\hline Source & Dependent Variable & $\begin{array}{l}\text { Type III } \\
\text { Sum of } \\
\text { Squares }\end{array}$ & df & Mean Square & $\mathrm{F}$ & Sig. \\
\hline \multirow[t]{2}{*}{$\begin{array}{l}\text { Corrected } \\
\text { Model }\end{array}$} & $\begin{array}{l}\text { Kemampuan_Berpi } \\
\text { kir_Kritis }\end{array}$ & $2394,017^{\mathrm{a}}$ & 1 & 2394,017 & 39,749 &, 000 \\
\hline & $\begin{array}{l}\text { Kemampuan_Berpi } \\
\text { kir_Kreatif }\end{array}$ & $570,417^{b}$ & 1 & 570,417 & 24,917 &, 000 \\
\hline \multirow[t]{2}{*}{ Intercept } & $\begin{array}{l}\text { Kemampuan_Berpi } \\
\text { kir_Kritis }\end{array}$ & $\begin{array}{r}104583,75 \\
0\end{array}$ & 1 & 104583,750 & $\begin{array}{r}1736,4 \\
59\end{array}$ & ,000 \\
\hline & $\begin{array}{l}\text { Kemampuan_Berpi } \\
\text { kir_Kreatif }\end{array}$ & 33938,817 & 1 & 33938,817 & $\begin{array}{r}1482,5 \\
28\end{array}$ & ,000 \\
\hline \multirow[t]{2}{*}{$\begin{array}{l}\text { Model_Pembela } \\
\text { jaran }\end{array}$} & $\begin{array}{l}\text { Kemampuan_Berpi } \\
\text { kir_Kritis }\end{array}$ & 2394,017 & 1 & 2394,017 & 39,749 &, 000 \\
\hline & $\begin{array}{l}\text { Kemampuan_Berpi } \\
\text { kir_Kreatif }\end{array}$ & 570,417 & 1 & 570,417 & 24,917 & ,000 \\
\hline \multirow[t]{2}{*}{ Error } & $\begin{array}{l}\text { Kemampuan_Berpi } \\
\text { kir_Kritis }\end{array}$ & 3493,233 & 58 & & & \\
\hline & $\begin{array}{l}\text { Kemampuan_Berpi } \\
\text { kir_Kreatif }\end{array}$ & 1327,767 & 58 & 22,893 & & \\
\hline \multirow[t]{2}{*}{ Total } & $\begin{array}{l}\text { Kemampuan_Berpi } \\
\text { kir_Kritis }\end{array}$ & $\begin{array}{r}110471,00 \\
0\end{array}$ & 60 & & & \\
\hline & $\begin{array}{l}\text { Kemampuan_Berpi } \\
\text { kir_Kreatif }\end{array}$ & 35837,000 & 60 & & & \\
\hline \multirow[t]{2}{*}{ Corrected Total } & $\begin{array}{l}\text { Kemampuan_Berpi } \\
\text { kir_Kritis }\end{array}$ & 5887,250 & 59 & & & \\
\hline & $\begin{array}{l}\text { Kemampuan_Berpi } \\
\text { kir_Kreatif }\end{array}$ & 1898,183 & 59 & & & \\
\hline
\end{tabular}

a. $\mathrm{R}$ Squared =,407 (Adjusted R Squared =,396)

b. $\mathrm{R}$ Squared =,301 (Adjusted R Squared =,288)

Hasil pengujian hipotesis membuktikan bahwa ada perbedaan kemampuan berpikir kritis dan kemampuan berpikir kreatif kimia secara bersama-sama antara kelompok mahasiswa yang belajar dengan model PBM dengan kelompok mahasiwa yang belajar dengan model ekspositori. Hal ini disebabkan oleh pembelajaran berbasis masalah merupakan suatu model pembelajaran yang mengkonfrontasikan mahasiswa dengan masalah-masalah praktis dan menuntut keaktifan mahasiswa dalam memecahkan masalah-masalah. Pembelajaran berbasis masalah memberikan kesempatan kepada mereka untuk mengembangkan kemampuan berpikir kritisnya melalui proses pemecahan masalah yang kompleks dalam kelompok diskusi kecil sehingga kemampuan mengidentifikasi, evaluasi, penalaran logis, interpretasi mahasiswa menjadi lebih baik. Pembelajaran yang mengakomodasi model PBM mampu mengungguli model pembelajaran ekspositori dalam hal pembentukan kemampuan berpikir kreatif. Model PBM merupakan model yang memberikan kesempatan mahasiswa untuk mengembangkan kemampuan berpikir kreatif melalui masalah-masalah yang bersifat open-ended. Pembelajaran berdasarkan masalah yaitu sebuah model pembelajaran yang dimulai dengan adanya masalah, kemudian mahasiswa memperdalam pengetahuannya 
tentang apa yang mereka telah ketahui dan apa yang mereka perlu ketahui untuk memecahkan masalah tersebut sehingga menuntut mereka untuk aktif, kritis dan kreatif dalam memecahkan masalah, mahasiswa diberi kebebasan untuk menyampaikan ide pikiran mereka dalam menyelesaikan masalah.

Hasil penelitian ini sesuai dengan penelitian Noer (2009) bahwa peningkatan kemampuan berpikir kritis matematis siswa yang mendapatkan pembelajaran matematika dengan PBM lebih baik daripada siswa yang mendapatkan pembelajaran secara konvensional. Demikian halnya dengan penelitian yang dilakukan oleh Nurhayati dkk (2013) berdasarkan hasil penelitiannya disimpulkan bahwa model PBM dapat meningkatkan kreativitas berpikir siswa. Kemampuan pemecahan masalah, berpikir kritis dan berpikir kreatif merupakan hakekat tujuan pendidikan dan menjadi kebutuhan bagi mahasiswa untuk menghadapi dunia nyata (Santyasa, 2004).

Model pembelajaran ekspositori dilakukan dengan cara menyampaikan materi kuliah secara langsung secara verbal dari dosen kepada mahasiswa sehingga kental dengan teacher-centered. Pembelajaran ini memberikan sedikit kesempatan mahasiswa untuk mengembangkan kemampuan berpikir kritis dan kreatif dalam memecahkan masalah. Hal ini kurang memberikan peluang bagi mahasiswa bekerja mandiri sehingga mahasiswa menjadi kurang aktif, kritis dan kreatif untuk mencari jawaban sendiri masalah yang dihadapinya dan lebih sering mengandalkan teman-temannya yang mempunyai kemampuan lebih, akibatnya mahasiswa kurang memahami konsep-konsep materi yang dipelajarinya

Hasil analisis deskripsi data menunjukkan rata-rata skor kemampuan berpikir kritis mahasiswa yang diberi model PBM $(48,9)$ lebih tinggi dari skor kemampuan berpikir kritis mahasiswa yang diberi model ekspositori $(35,43)$. Hasil penelitian ini sesuai dengan hasil penelitian I Ketut Reta pada siswa kelas X SMA yang berjudul Pengaruh Model Pembelajaran Berbasis Masalah terhadap Ketrampilan Berpikir Kritis ditinjau dari Gaya Kognitif Siswa, hasil penelitiannya membuktikan bahwa terdapat perbedaan yang signifikan ketrampilan berpikir kritis antara kelompok siswa yang diajar dengan dengan model pembelajaran berbassis masalah dan kelompok siswa yang belajara dengan model pembelajaran konvensional.

Barbara (2001) menyatakan: diterapkannya Pembelajaran Berdasarkan Masalah, dapat melatih mahasiswa berpikir kritis, menganalisis dan memecahkan masalah komplek, dapat bekerja secara kooperatif di dalam tim kecil, meningkatkan kemampuan berkomunikasi dengan efektif baik verbal maupun tertulis. Dalam tahapan pembelajaran yang diawali dengan orientasi mahasiswa pada masalah aktual dan autentik, lalu dilanjutkan dengan mengorganisasi mahasiswa dalam belajar, membimbing penyelidikan di dalam kelompok, mengembangkan dan menyajikan hasil karya, dan diakhiri dengan menganalisis dan mengevaluasi proses pemecahan masalah, mahasiswa secara individual dan juga dalam kelompok akan menganalisis masalah, mengidentifikasi dari inti permasalahan, mengidentifikasi apa yang harus diketahui dan apa yang harus mereka pelajari agar bisa memecahkan masalah, dan berkolaborasi untuk mengitegrasikan seluruh materi untuk menghasilkan suatu simpulan dan pemecahan masalah.

Hasil analisis deskripsi data menunjukkan rata-rata skor kemampuan berpikir kreatif mahasiswa yang diberi model PBM $(26,87)$ lebih tinggi dari skor kemampuan berpikir kreatif mahasiswa yang diberi model ekspositori (20,7). Hasil ini sesuai dengan penelitian yang telah dilakukan oleh Nurhayati (2013) bahwa Penerapan Model Pembelajaran Problem Based Learning (PBL) dapat meningkatkan kreativitas siswa kelas X SMA Al islam 1 di Surakarta. Munandar (2009) menyatakan: Kemampuan untuk melihat bermacam-macam kemungkinan suatu masalah merupakan bagian dari berpikir kreatif. Proses Pembelajaran Berbasis Masalah melatih dan mengembangkan kemampuan 
berpikir kreatif yang merupakan berpikir divergen meliputi kemampuan imajinasi, kelancaran, keluwesan dalam menyelesaikan masalah.

\section{PENUTUP}

\section{Simpulan}

Dari Penelitian ini disimpulkan bahwa terdapat perbedaan kemampuan berpikir kritis dan kemampuan berpikir kreatif secara bersama-sama antara kelompok mahasiswa yang belajar dengan model pembelajaran berbasis masalah dan model pembelajaran ekspositori.

\section{Saran}

Dari hasil penelitian dan kondisi yang ada dapat disampaikan beberapa saran diantaranya:

1. Hendaknya dalam mengajarkan kimia, dosen diharapkan dapat merancang dan mengembangkan suatu model pembelajaran yang dapat mengaktifkan mahasiswa untuk belajar dan mampu memecahkan masalah yang dihadapkan kepada mahasiswa, dan disarankan agar dosen dapat menerapkan model pembelajaran berbasis masalah (PBM) karena pada dasarnya pembelajaran berbasis masalah dalam pelaksanaannya menghadapkan mahasiswa pada masalah yang dikaitkan dengan permasalahan dalam kehidupan sehari-hari sehingga dapat mengembangkan kemampuan berpikir kritis dan kemampuan berpikir kreatif mahasiswa.

2. Penerapan langkah-langkah model pembelajaran perlu dipersiapkan dengan baik oleh dosen sehingga dapat melibatkan mahasiswa aktif secara langsung dalam pembelajaran

3. Kepada peneliti dan pemerhati pendidikan khususnya bidang pendidikan kimia. Karena penelitian ini baru sampai mengangkat pengaruh model pembelajaran terhadap kemampuan berpikir kritis dan kemampuan berpikir kreatif kimia, maka peneliti menyarankan kiranya para peneliti tersebut dapat melanjutkan penelitian pasca penelitian ini. Hal ini penting agar hasil penelitian ini bermanfaat sebagai penyeimbang teori maupun sebagai reformasi terhadap dunia pendidikan khususnya dalam penggunaan model pembelajaran.

\section{DAFTAR PUSTAKA}

Arends, R.I. 2007. Learning to Teach Belajar Untuk Mengajar buku 2, Terjemahan oleh Helly Prajitno Soetjipto, dan Sri Mulyantini Soetjipto. 2008. Yogyakarta. Pustaka Pelajar..

Barbara J. Duch, dkk. 2008. The Power of Problem Based Learning. 2001. h.6. Virginia: Stylus Publishing Bassham, G., Irwin, W., Nardone, H., \& Wallace, J. M Critical thinking: A student's introduction. 3nd Edition. New York: McGraw-Hill Company, Inc.

Fasco, D. 2001. Education and Creativity. Creativity Research Journal 2000- 2001, Vol. 13.

Filsaime, D. K. 2008. Menguak Rahasia Berpikir Kritis dan Kreatif. Jakarta. Prestasi Pustaka.

Hasratudin. 2010. Meningkatkan kemampuan berpikir kritis siswa SMP melalui pendekatan matematika realistik. Jurnal Pendidikan Matematika, 4(2).

Haswan, Elly. 2006. Pengaruh Metoda Pembelajaran terhadap Hasil Belajar Fisika ditinjau dari Gaya Kognitif Siswa (Eksperiment pada Kelas XI Jurusan IPA MAN Insan Cendekia Serpong Banten). Jakarta: Program Pasca Sarjana UNJ. 
Hidayat, Sony. 2011. Pengaruh Model Problem Based Learning terhadap Hasil Belajar Kimia siswa pada konsep Termokimia (Eksperimen di SMA Negeri 3 Tangerang Selatan). Skripsi. Jakarta: UIN Syarif Hidayatullah

McGregor, D. 2007. Developing Thinking Developing Learning: A Guide to Thinking Skills in Education. Berkshire: Open University Press.

Munandar, U. 2009. Pengembangan Kreativitas Anak Berbakat. Jakarta: Rineka Cipta.

Nasution, S. 2008. Berbagai Pendekatan dalam Proses Belajar \& Mengajar. Jakarta: PT. Bumi Aksara.

Nurhayati. 2013. Peningkatan kreativitas dan prestasi belajar pada materi minyak bumi melalui penerapan model pembelajaran problem based learning (PBL) dengan media crossword. Jurnal Pendidikan Kimia (JPK), 2 (4).

Reta, I Ketut. 2012. Pengaruh Model Pembelajaran Berbasis Masalah Terhadap Ketrampilan Berpikir Kritis ditinjau dari Gaya Kognitif Siswa. Artikel Tesis Program Studi Pendidikan IPA, Program Pascasarjana, Undiksha, Singaraja.

Rohaeti. 2010. Critical and creative mathematical thinking of junior high school students. Jurnal Educationist, 4 (2).

Santyasa, I.W. 2004. Model Problem Solving dan Reasoning sebagai alternatif Pembelajaran Inovatif. Makalah. Disajikan dalam Konvensi Nasional Pendidikan Indonesia V. Bali: IKIP Negeri Singaraja.

Trianto. 2007. Model-model Pembelajaran Inovatif Konstruktivistik. Jakarta: Prestasi Pustaka. 